\title{
On the training of soft skills in a Peruvian University: Strengths and weaknesses
}

\author{
Laberiano Andrade-Arenas, Doctor ${ }^{1}$, Frank Andrade -Chaico, Bachiller ${ }^{2}$ \\ ${ }^{1}$ Universidad de Ciencias y Humanidades, Perú, landrade@uch.edu.pe, ${ }^{2}$ Pontificia Universidad Catolica \\ del Perú,Perú, frank.andrade@ @ucp.pe
}

\begin{abstract}
Soft skills, which are interpersonal and social skills, are very important in the job market. Skills like teamwork, oral expression and leadership could make a difference when two or more candidates for a job vacancy have similar qualifications. The Peruvian job market is not an exception to this, since research shows that headhunters prioritize soft skills in 9 out of 10 personal selections. Therefore, this work puts forward an analysis to determine in which skills at a Peruvian university students are being trained and which of these skills undergraduate students consider are important for the job market. To obtain this information, 71 undergraduate students from the electronic engineering and computer science programs were surveyed. First, it was found that more than $62 \%$ of the participants considered that skills like teamwork and leadership are very important for the job market; however, $12 \%$ and $14 \%$ states that they are badprepared in these skills at university respectively. In addition, 91\% participants considered that foreign language skills are important or very important, nevertheless, this stands as the worst skill in which they are being prepared at university among 11 skills listed in the survey. Finally, the Chi-Square Test for Independence was used to determine the dependence between gender and the importance of any listed skill. It is expected that this work serves as a guide to educational authorities from Peru to promote a better preparation in soft skills at universities.

Index Terms - soft skills, undergraduate students, job market, Peruvian university
\end{abstract}

\section{INTRODUCTION}

Soft skills are described as a combination of interpersonal and social skills and are usually developed through personal experience and reflections [1]. dssd

Nowadays, soft skills are highly important in any job market. For Information Systems professionals, such as software engineers, support specialists, network and systems administrators, database administrators, and systems analysts, soft skills have typically been important to the user support staffing area; however, a study shows that these skills are becoming increasingly important to all areas of IS [2]. Ninetysix percent of 330 executives surveyed by the University of Phoenix in 2005 rated communication and interpersonal skills as the most valuable employee trait, followed by aptitude and desire to grow at $95 \%$ and teamwork at $93 \%$ [3]. To be successful in the job market, candidates for jobs have to bring along a "competitive edge" that distinguishes them from other candidates with similar qualifications [4].

Digital Object Identifier (DOI):

http://dx.doi.org/10.18687/LACCEI2020.1.1.261

ISBN: 978-958-52071-4-1 ISSN: 2414-6390
If a college graduate has to be trained in their oral expressions, in how to do a proper presentation or how to talk in a pleasant and winning manner with colleagues and customers, then this graduate will not be considered as a quick starter in the workplace [4]. Nowadays employers look for soft skills and attributes when recruiting as a way of predicting success in the workplace [5].

The Peruvian job market also considers soft skills important. According to a Peruvian agency, headhunters prioritize soft skills in 9 out of 10 personal selections [6]. They state that adapting to change, teamwork and leadership skills are the most sought after in candidates.

All Peruvian universities, according to the law $\mathrm{N}^{\mathrm{o}} 30220$, should have subjects like Oratory, Leadership, Ethics, and Theater, in the first 4 semesters of studies in Peruvian universities [7]. These subjects help to reinforce the development of soft skills. Having said that, it is still not completely clear how good or bad is the preparation of the development of soft skills in Peruvian universities. In order to have a better understanding of this point, a survey was taken among 71 undergraduate students at the University of Science and Humanities (in Spanish: Universidad de Ciencias y Humanidades, UCH).

In this article, we engaged in research to get information about the importance of soft skills in the job market and the soft skills preparation level in a Peruvian university from the perspective of undergraduate students of the electronic engineering and computer science programs.

\section{Methodology}

\section{A. Survey}

Volunteers from the above mentioned programs were recruited during April 2019 at UCH. There were not particular criteria for participation in the survey. The population consisted of 59 men and 12 women. The range of ages was around an average $(\mu)$ of 20.7 years old with a standard deviation $(\sigma)$ of 4.5. Participants were asked to answer two rating scale questions. These 2 main questions used the same set of subquestions that are presented in table I. The first question (Q1) was about the importance of soft skills in the job market. The second question (Q2) was about the level of preparation in the development of soft skills at UCH.

\section{B. Statistical Analysis}

Once we surveyed all the participants we classified the answers by gender and we used the Chi-Square Test for

$\mathbf{1 8}^{\text {th }}$ LACCEI International Multi-Conference for Engineering, Education, and Technology: "Engineering, Integration, and Alliances for a Sustainable Development" "Hemispheric Cooperation for Competitiveness and Prosperity on a Knowledge-Based Economy", 27-31 July 2020, Virtual Edition. 
Independence [8] to determine whether gender has a relation to a specific skill.

First, we state the null hypothesis $\left(H_{0}\right)$ and the alternative hypothesis $\left(H_{1}\right)$ for one of the skills listed in the survey:

$H_{0}$ : Gender and the n-Skill are independent

$H_{1}$ : Gender and the n-Skill are not independent

where the variable "Gender" has r levels, and the variable "n-Skill" has c levels. The null hypothesis states that the "Gender" is not associated with the level of "n-Skill"; that is, the variables are independent. In this study the variable gender has 2 levels: Male and Female then $r=2$. The levels for the variable n-Skill are "Less important" and "Important + Very Important" then $\mathrm{c}=2$.

To accept or reject $H_{0}$ we had to compare the $p$-value and the significance level $(\alpha)$ as shown in the following equation (for this analysis, we considered the significance level equal to 0.05$)$ :

$$
y=\left\{\begin{array}{l}
H_{0} \text { is not accepted, p-value }<0.05 \\
H_{0} \text { is accepted, p-value }>0.05
\end{array}\right.
$$

To calculate the $p-$ value we need the chi-square random variable $\left(\chi^{2}\right)$ and the degrees of freedom (DF). To calculate $\chi^{2}$ we used the test statistics defined by the following:

$$
\chi^{2}=\sum \frac{\left(O_{r, c}-E_{r, c}\right)^{2}}{E_{r, c}},
$$

where $O_{r, c}$ is the observed frequency count at level $\mathrm{r}$ of the variable "Gender" and level c of the variable "n-Skill", and $E_{r, c}$ is the expected frequency count at level $\mathrm{r}$ of the variable "Gender" and level c of the variable "n-Skill". The distribution of the obtained frequency according to "Gender" for a "nSkills" are shown in table II; for example, $O_{1,2}$ is $n_{12}$. To obtain the expected frequency, we used the following:

$$
E_{r, c}=\frac{\left(n_{r} * n_{c}\right)}{n}
$$

where $E_{r, c}$ is the expected frequency count for level $\mathrm{r}$ of the variable "Gender" and level c of variable the "n-Skill", $n_{r}$ is the total number of sample observations at level $r$ of variable "Gender", $n_{c}$ is the total number of sample observations at level c of the Variable "n-Skill", and $n$ is the total sample size

TABLE I

QUESTION SET FOR Q1 AND Q2

\begin{tabular}{c}
\hline \hline List of skills \\
\hline Master area of expertise \\
Coordination of activities \\
Teamwork \\
Work under pressure and achieve goals \\
Write reports and documents \\
Leaderships \\
Present ideas in front of people \\
Use basic IT tools \\
Have a basic knowledge in different fields \\
Use of software related to area of expertise \\
Read, write and speak foreign languages \\
\hline
\end{tabular}

TABLE II

CHI-SQUaRe TEST FOR INDEPENDENCE FOR THE N-SKILL

\begin{tabular}{cccc}
\hline \hline Gender & LI & I+VI & Total \\
\hline Man & $n_{11}$ & $n_{12}$ & $n_{r=1}$ \\
Women & $n_{21}$ & $n_{22}$ & $n_{r=2}$ \\
\hline Total & $n_{c=1}$ & $n_{c=2}$ & $n$ \\
\hline
\end{tabular}

$(n=71)$. In addition, to calculate the degrees of freedom we used equation 4 .

$$
D F=(r-1) *(c-1),
$$

Once we calculted $\chi^{2}$ and DF, the $p$-value was estimated. After calculating $p$-value, we compared it with the significance value (0.05) to determine the association of the variables analyzed.

\section{RESULTS AND DISCUSSION}

\section{A. Results of the survey}

Some of the most relevant results for Q1, presented in table III, indicate that $8.45 \%$ of the participants do not consider foreign languages and basic knowledge in different fields as important skills in the job market. These results are consistent with a survey answered by graduate students from private universities carried out by the Peruvian agency INEI in October 2015 [9]. In this survey, 52.5\% of the participants described that they received a good preparation in their universities for the skill "basic knowledge in other fields" (ranked 10 in 12 options listed), whereas $40.5 \%$ described the preparation for the skill "reading, writing and speaking foreign languages" as good in their universities (ranked 12 in 12 options). The lack of good preparation in these skills at Peruvian universities could be one reason why some of them in this survey did not also consider them relevant.

Results for Q2, presented in table III, indicate that $24 \%$ of the participants consider that they receive a bad preparation in foreign languages at university. This skill ranks as the worst skill prepared in universities among the 11 skills listed in the survey. The results also agree with research made by INEI in 2015 [9] where only $53.6 \%$ of the graduate students surveyed described the preparation in foreign languages in

TABLE III RESULTS FOR Q1 AND Q2

\begin{tabular}{ccccc}
\hline \hline Skills listed in the & \multicolumn{2}{c}{ Q1 } & \multicolumn{2}{c}{ Q2 } \\
survey & LI & I+VI & BP & GP+EP \\
\hline Master area of expertise & 0 & 71 & 2 & 69 \\
Coordination of activities & 1 & 70 & 2 & 69 \\
Teamwork & 1 & 70 & 9 & 62 \\
Work under pressure and achieve goals & 8 & 63 & 7 & 64 \\
Write reports and documents & 4 & 67 & 4 & 67 \\
Leaderships & 5 & 66 & 10 & 61 \\
Present ideas in front of people & 5 & 66 & 8 & 63 \\
Use basic IT tools & 3 & 68 & 2 & 69 \\
Have basic knowledge in different fields & 6 & 65 & 8 & 63 \\
Use of software within area of expertise & 4 & 67 & 4 & 67 \\
Read, write and speak foreign languages & 6 & 65 & 17 & 54 \\
\hline
\end{tabular}


their universities as good or excellent (ranked 12th in a list of 12 well-prepared skills). Moreover, results for Q2 also showed that $14 \%$ and $12.68 \%$ of the participants consider that they receive a bad preparation in the skills leadership and teamwork respectively. The results for both skills agree with the research mentioned above where $16.6 \%$ do not consider that the preparation for the skill leadership in their universities was good or excellent and $12.4 \%$ affirmed similarly for the skill teamwork. Peruvian universities should focus in the development of teamwork since it is one of the top $10 \mathrm{soft}$ skills that are perceived as the most important by business executives [10]

\section{B. Chi-Square Test for Independence}

To determine the dependence between gender and the importance of each skill evaluated, we used the results obtained for Q1 and we classified them by gender. The classification is presented in table IV.

TABLE IV

Q1 CLASSIFIED BY GENDER

\begin{tabular}{cccc}
\hline \hline Skills & Gender & LI & I+VI \\
\hline Master area of expertise & Male & 0 & 60 \\
Coordination of activities & Female & 0 & 12 \\
Teamwork & Male & 1 & 59 \\
& Female & 0 & 12 \\
& Male & 1 & 59 \\
Work under pressure and achieve goals & Female & 0 & 12 \\
Write reports and documents & Male & 7 & 52 \\
& Female & 1 & 11 \\
& Male & 3 & 56 \\
Leaderships & Female & 1 & 11 \\
& Male & 4 & 55 \\
Present ideas in front of people & Female & 1 & 11 \\
& Male & 4 & 56 \\
& Female & 1 & 11 \\
Have a basic knowledge in different fields & Male & 2 & 57 \\
& Female & 1 & 11 \\
& Male & 6 & 54 \\
Use of software related to area of expertise & Female & 0 & 12 \\
& Male & 2 & 58 \\
Read, write and speak foreign languages & Female & 2 & 10 \\
& Male & 4 & 56 \\
& Female & 2 & 10 \\
\hline
\end{tabular}

As an example, we stated the null hypothesis $\left(H_{0}\right)$ and the altenative hypothesis $\left(H_{1}\right)$ for "Use of software related to area of expertise".

\section{$H_{0}$ : Gender and "Use of software related to area of expertise" are independent \\ $H_{1}$ : Gender and "Use of software related to area of expertise" are not independent}

Then we extract the information obtained for this variable and build table V. Following equation 2, 3 and 4 we obtained the $p-v a l u e$ for the variable:

$$
p-\text { value }=0.07
$$

In the same way, we obtained the $p-$ value for each skill and they are presented in table VI.
TABLE V

CHI-SQUARE TEST FOR INDEPENDENCE FOR THE SKILL "USE OF SOFTWARE RELATED TO AREA OF EXPERTISE"

\begin{tabular}{cccc}
\hline \hline Gender & LI & I+VI & Total \\
\hline Man & 2 & 58 & 60 \\
Women & 2 & 10 & 12 \\
\hline Total & 4 & 68 & 72
\end{tabular}

TABLE VI

P-VALUE FOR EACH SKILL

\begin{tabular}{cc}
\hline \hline Skills & P-value \\
\hline Master area of expertise \\
Coordination of activities & - \\
Teamwork & 0.65 \\
Work under pressure and achieve goals & 0.65 \\
Write reports and documents & 0.72 \\
Leaderships & 0.66 \\
Present ideas in front of people & 0.85 \\
Use basic IT tools & 0.84 \\
Have a basic knowledge in different fields & 0.44 \\
Use of software related to area of expertise & 0.25 \\
Read, write and speak foreign languages & 0.07 \\
\hline
\end{tabular}

${ }^{a}$ There was not participants who considered the variable "Master area of expertise" as "less important" therefore it was not possible to calculate its $p$-value.

None of the $p$-values obtained is less than the significance level considered (0.05) then the hypothesis null is accepted for each variable. However "Use software related to area of expertise" is very close to the significance level. This can hint to the possibility that if we survey more women, it could be shown that there is an association between gender and the importance of the use of software related to the area of expertise. This hypothesis is consistent with the results obtained in a survey answered by 630 Anglo American undergraduates where it was found that females used e-mail more than males, consistent with their stronger motive for interpersonal communication, while male used the Web more than did females, consistent with their stronger motive for information. In addition, females reported less computer self-efficacy and less favorable attitudes about the importance of computer technology than did males [11]. Furthermore, a study carried out in schools, with 340 fifth and sixth-grade students, shows that more girls (13.3\%) than boys $(6.3 \%)$ said that they did not use computers and more girls $(28.3 \%)$ than boys $(16.1 \%)$ did not use the internet outside school) [12]. The lack of interest showed by girls in the use of computer since elementary school could be the reason why when they grow up present less favorable attitudes towards the importance of computer technology like the use of software related to the area of expertise. 


\section{CONCLUSIONS}

In this work a case was presented about the training of soft skills in a Peruvian University. The most important points are summarized:

1) More than $60 \%$ of the participants described "Master area of expertise", "Use software related to area of expertise", "Teamwork" and "Leadership" as very important skills. In addition, it should be noted that $12 \%$ considered that they receive a bad preparation for the last 2 skills mentioned before and they rank in the top 3 of the skills that are bad-prepared at $\mathrm{UCH}$.

2) The UCH should focus in the development of teamwork in their students since it is one of the top 10 soft skills that are perceived as the most important by business executives

3) Most undergraduate students (91\%) in this survey consider that foreign language skills are important or very important. However, $24 \%$ state that they receive a bad preparation in university. This skill ranks as the worst skill prepared in universities among the 11 skills listed in the survey.

4) There was not found a relation between the gender of the participants with the importance of any skill listed in this survey. However, a bigger sample might make the importance of the skill "Use software related to area of expertise" dependent on the gender of the participant.

5) It is hoped that this study serves education authorities from Peru such as the SUNEDU (in Spanish: Superintendencia Nacional de Educación Superior Universitaria) or the Ministry of Education in order to promote a better preparation for skills such as Foreign languages, Teamwork and Leadership in universities.

\section{REFERENCES}

[1] J. Dixon, C. Belnap, C. Albrecht, and K. Lee, "The importance of soft skills," Corporate Finance Review, vol. 14, pp. 35 - 38, 062010.

[2] C. L. Noll and M. Wilkins, "Critical skills of is professionals: A model for curriculum development," Journal of Information Technology Education, vol. 1, pp. 144-154, 2002.

[3] M. Ellis, E. Kisling, and R. G. Hackworth, "Teaching soft skills employers need," Community College Journal of Research and Practice, vol. 38 , pp. $433-453,2014$

[4] B. Schulz, "The Importance of Soft Skills: Education beyond academic knowledge," Journal of Language and Communication, pp. 146 - 154 062008.

[5] M. A. al mamun, "The soft skills education for the vocational graduate: Value as work readiness skills," British Journal of Education, Society \& Behavioural Science, vol. 2, pp. 326-338, 2012.

[6] Gestión. (2019) Headhunters priorizan habilidades blandas en 9 de cada 10 procesos de selección de personal. [Online]. Available: https://gestion.pe/economia/empresas/adaptacioncambio-equipo-son-habilidades-blandas-buscadas-headhunters-270592

[7] Ministerio de Educación. (2014) Ley universitaria: Ley n.30220. [Online]. Available: http://www.minedu.gob.pe/reformauniversitaria/pdf/ley_universitaria.pdf

[8] M. M. L., "The chi-square test of independence," Biochemia medica, vol. 23, no. 2, p. 143-149, 2013.

[9] Instituto Nacional de Estadísticas e Informática, "Desarrollo de habilidades y competencias," in Encuesta nacional a egresados universitarios $y$ universidades 2014, October 2015, pp. 130-132.

[10] M. M. Robles, "Executive perceptions of the top 10 soft skills needed in today's workplace," Business Communication Quarterly, vol. 75, no. 4, pp. 453-465, 2012

[11] L. A. Jackson, K. S. Ervin, P. D. Gardner, and N. Schmitt, "Gender and the internet: Women communicating and men searching," Sex Roles A Journal of Research, vol. 44, no. 5-6, p. 363, 2001.

[12] I. Vekiri and A. Chronaki, "Gender issues in technology use: Perceived social support, computer self-efficacy and value beliefs, and computer use beyond school," Computers \& Education, vol. 51, no. 3, pp. 1392 $-1404,2008$ 